\title{
Мощность земной коры территории Республики Нигер по данным стохастической интерпретации гравитационного поля
}

\author{
(C) 2020 В. Н. Глазнев ${ }^{1,2}$, И. А. Якуба ${ }^{1 凶}$ \\ ${ }^{1}$ Воронежский государственный университет, Университетская пл., 1, \\ 394018, Воронеж, Российская Федерация \\ ${ }^{2}$ Геологический институт Кольского научного центра РАН, ул. Ферсмана, 14, \\ 184209, Апатиты, Российская Федерация
}

\begin{abstract}
Аннотация
Введение: Территория Республики Нигер и прилегающих стран Западной Африки относится к областям слабо обеспеченным данными наземных и аэрогеофизических съёмок, нацеленными на региональное изучение земной коры. Цель настоящей статьи - обобщение данных наземных и спутниковых съёмок гравитационного поля, предназначенных для изучения земной коры в условиях неполноты исходной геолого-геофизической информации. Задачей последующей интерпретации выявляемых гравитационных аномалий является создание обновлённой схемы мощности земной коры территории Республики Нигер, для которой до настоящего времени известно несколько существенно различных вариантов строения коры.

Методика: Объединение результатов наземных гравиметрических съёмок 60-х годов и современных цифровых спутниковых моделей гравитационного поля с целью формирования синтетической модели аномального поля, пригодной для последующей его интерпретации на основе использования самой общей стохастической модели с сингулярными источниками в горизонтальном слое.

Результаты и обсуждение: Результаты интерпретации гравитационных аномалий на основе стохастической модели источников поля позволили составить карту оценок мощности земной коры для территории исследований и сопредельных областей. Построенная схема, сопоставленная с результатами предшествующих работ по определению мощности земной коры, демонстрирует значимые различия моделей коры, особенно в восточной части региона. Выполненный анализ статистической связи полученных оценок мощности земной коры и усреднённых величин рельефа территории демонстрирует некоторую тенденцию связи между этими параметрами, что позволяет сделать вывод о частичной изостатической компенсации для крупных блоков коры региона. Анализ данных по мощности земной коры и схемы поверхностных геолого-тектонических элементов строения территории Республики Нигер позволил наметить связи геодинамической эволюции коры с положением границы раздела кора-мантия.

Заключение: Составленная синтетическая модель гравитационного поля в редукции Буге может служить достоверной основой при решении задач регионального гравиметрического моделирования. Результаты стохастической интерпретации гравитационного поля региона позволили получить оценки мощности земной коры изучаемой территории в рамках принятой модели слоя со случайным распределением плотностных неоднородностей. Сопоставление полученных оценок мощности земной коры с данными стандартной модели CRUST1
\end{abstract}

\section{Контент доступен под лицензией Creative Commons Attribution 4.0 License.}

\footnotetext{
Якуба Ибрагим Абдоу, e-mail: yibrahimabdou@yahoo.fr
} 
демонстрирует существенное несоответствие последней для изучаемой территории. Анализ новых данных о мощности земной коры позволил наметить особенности глубинного строения блоков литосферы, отождествляемых с крупными элементами тектонической схемы территории Республики Нигер.

Ключевые слова: Республика Нигер, гравитационное поле, стохастическая интерпретация, мощность земной коры

Для циттирования: Глазнев В. Н., Якуба И. А. Мощность земной коры территории Республики Нигер по данным стохастической интерпретации гравитационного поля // Вестник Воронежского государственного университета. Серия: Геология. 2020. №4. С. 46-58. DOI: https://doi.org/10.17308/geology.2020.4/3126

\section{Введение}

Создание комплексных моделей глубинного строения земной коры крупных континентальных регионов традиционно выполняется на основе совместной интерпретации сейсмических, гравиметрических и геотермических данных, что позволяет получать достаточно надёжные геолого-геофизические результаты. Эффективные примеры таких интерпретационных построений, известные для различных регионов мира [1-6 и др.], демонстрируют возможности построения содержательных геологических моделей крупных континентальных литосферных блоков на основе решения обратных задач геофизики. В основу таких построений положены, как правило, достоверные результаты геофизических данных и сводные материалы о петрофизических свойствах пород изучаемого региона, для совокупности которых можно сформулировать итерационное решение комплексной обратной задачи в общей постановке [2, 7, 8]. Однако такие идеальные позиции решения комплексной обратной задачи на практике реализуют- ся не всегда, поскольку для многих регионов мира отсутствуют детальные сейсмические материалы о строении земной коры, а полнота описания гравиметрических и геотермических данных характеризуется редкой сетью полевых наблюдений. В этих условиях при создании моделей строения коры крупных регионов следует использовать развитые методы стохастических оценок глубинных характеристик изучаемой среды [2, 9], а также глобальные спутниковые данные о геофизических полях [10] и обобщённые модели строения литосферы Земли [11-13].

Территория Республики Нигер и прилегающих стран Западной и Экваториальной Африки (рис. 1) относится к территориям, слабо обеспеченным наземными и аэрогеофизическими съёмками. Поэтому привлечение указанных выше обобщённых моделей является вполне уместным при геофизическом моделировании строения коры. В предлагаемой работе рассматриваются методы и результаты оценок мощности модели земной коры для территории Республики

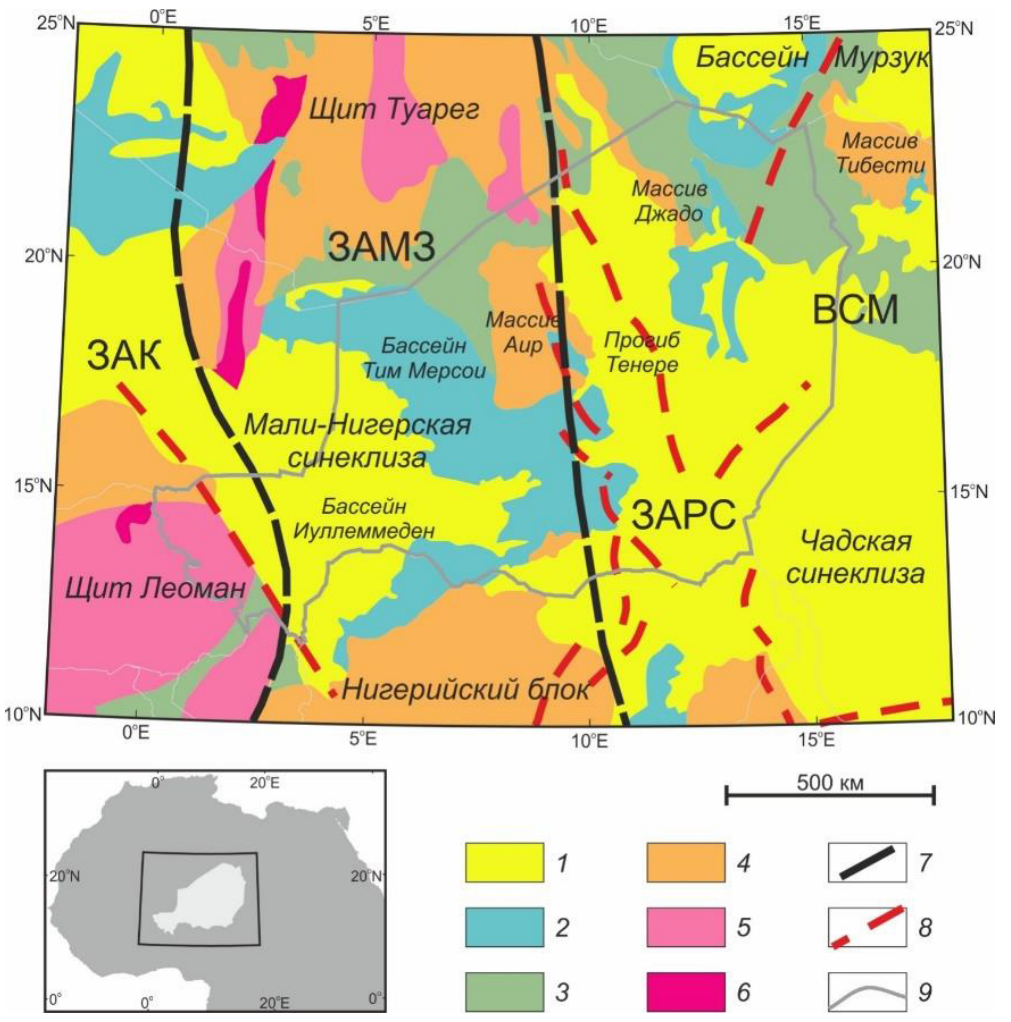

Рис. 1. Геолого-тектоническая схема территории Республики Нигер и прилегающих стран, составлена по $[18,20,21,32]: 1$ четвертичный период; 2 - мезозой-кайнозой; 3 палеозой; 4 - мезо-неопротерозой; 5 палеопротерозой; 6 - архей; 7 - границы литосферных кратонов; 8 - крупные системы разломов; 9 - государственные границы. Аббревиатуры: $3 A K-$ Западно-Африканский кратон; $B C M$ - Восточно-Сахарский мегакратон; $3 A M 3$ - Западно-Африканская мобильная зона; ЗАРC - Западно-Африканская рифтовая система.

[Fig. 1. A sketch geology-tectonic map of the Republic of the Niger and the surrounding countries, compiled by [18, 20, 21, 32]: 1 - Quaternary; 2 - Mesozoic-Cenozoic; 3 - Paleozoic; 4 - MesoNeoproterozoic; 5 - Paleoproterozoic; 6 - Archean; 7 - boundaries of lithospheric cratons; 8 - large fault systems; 9 - state borders. Abbreviations: $3 A K-$ West African Craton; $B C M$ - East Sahara Megacraton; $3 A M 3$ - West African Mobile Zone; $3 A P C$ - West African Rift System.] 
Нигер в условиях неполноты исходной геологогеофизической информации. Основной геологической задачей такого геофизического моделирования является разработка обновлённой региональной схемы гравитационных аномалий и геолого-геофизической модели строения земной коры территории Республики Нигер. Такие гравитационные данные будут являться исходной основой при детальном изучении геологического строения верхней части земной коры изучаемой площади и выявления связей её геологического строения с размещением основных видов полезных ископаемых, играющих важную роль в экономике Республики Нигер. Геологическая трактовка материалов плотностного моделирования должна базироваться на концептуальных геологических моделях региона и опираться на развитые методы геолого-геофизического анализа данных [14-17 и др.].

\section{Краткий обзор геологии региона}

Современная структура коры Африканского континента (рис. 1) является результатом сложной геодинамической эволюции литосферы, развивавшейся на протяжении более 3.2 млрд лет $[18,19]$. Основные этапы этой эволюции, согласно [20, 21], включают: образование ювенильной коры и стабилизацию кратонов северной Африки в архейское время; существенную переработку коры в протерозойское время; последующий Панафриканский орогенез (в интервале 450-600 млн. лет) и перегруппировка блоков. Следы этого этапа эволюции суперконтинента просматриваются в соотношении границ ЗападноАфриканского кратона и Восточно-Сахарского мегакратона с разделяющий их Западно-Африканской мобильной зоной (рис. 1). В мезозойский период последовал распад суперконтинента Гондвана, а в кайнозое имел место подъём горячего мантийного материала в области Западно-Африканской мобильной зоны [22], проявленный на поверхности в виде молодого вулканизма и реактивации тектонических процессов в Западно-Африканской рифтовой системе.

Фундамент докембрийского возраста, относящийся к щиту Туарег [19], обнажается в северной и центральной части территории в пределах нагорья Ахаггар (юг Алжира - север Республики Нигер). Собственно, щит Туарег представляет составной ансамбль архейскопротерозойских террейнов [23] в области Западноафриканской мобильной зоны, ориентированных в субмеридиональном направлении и в разной мере подверженных более поздней тектонической переработке и интенсивному разновозрастному магматизму $[22,23]$. Геодинамическая специфика этого этапа определялась частичным плавлением пород нижней коры в результате деламинации континентальной литосферной мантии региона [23].

Краевые фрагменты щита Туарег слагают массивы Аир и Джадо (см. рис. 1). Массив Аир включает в себя докембрийское основание, палеозойский комплекс кольцевых интрузий и область кайнозойского вулка- низма. Докембрийский фундамент разделяют на две формации [18]: гетерогенный метаморфический комплекс и комплекс гранитоидных интрузий панафриканского возраста. Анорогенный комплекс кольцевых интрузий палеозойского возраста [18] характеризуются разнообразием типов пород. Массив Джадо имеет двухъярусное строение с гранито-гнейсами в основании и нижнепротерозойскими сланцами в верхней части [18]. Архейский гранито-гнейсовый комплекс перекрыт метаморфизованной терригенной континентальной серией раннепротерозойского возраста.

Нигерийский блок (рис. 1), лежащий в ЗападноАфриканской мобильной зоне, представляет северный фрагмент плато Джос (Нигерия). В пределах блока фундамент сложен глубокометаморфизованными породами архея и палеопротерозоя [18, 19], подвергшимися на стадии панафриканского орогенеза термальной и структурной переработке. Комплексы мезозоя Нигерийского блока, представленные щелочными породами, близки по составу к комплексам массива Аир, что трактуется как результат длительного функционирования мантийных горячих точек [22].

На юго-западе региона (см. рис. 1) выходят породы северо-восточной окраины щита Леоман [25], в пределах которого выделяют архейскую область на северо-западе и область Бауле-Мосси на юго-востоке. Граница между этими областями картируется нечётко в силу последовательного омоложения архейских формаций в процессе эбернской орогении (с возрастом 2000-2200 млн. лет). Породы щита, в пределах нашего региона, сформированы серией крупных вулканогенно-осадочных бассейнов и линейных зеленокаменных поясов палеопротерозойского возраста [26], разделённых большими полями архейских гранитоидов [19].

Ядро массива Тибести слагают метаморфизованные комплексы основных вулканогенно-осадочных пород с возрастом от архея до мезопротерозоя [18, 19]. Обрамление пород ядра массива представлено более молодыми слабометаморфизованными породами палеозойского возраста, с интрузиями щелочных пород кислого состава. В верхней части разреза породы массива перекрываются третичными вулканическими базальтами и андезитами. Предполагается, что массив Тибести сформирован в результате деятельности долгоживущей мантийной горячей точки, порождающей региональный подъем территории и утончение литосферы с проявлением щелочного магматизма [27].

Современные крупные осадочные бассейны региона сформированы в процессе реактивации тектонических структур, заложенных на этапе панафриканской орогении. Мали-Нигерская синеклиза, пространственно разделяемая на области бассейнов Тим Мерсои и Иуллеммеден, согласно данным [28] сложена последовательно: ордовикско-пермскими морскими и континентально терригенными породами, триасово-меловой континентальной толщей, олигоцен-неогеновыми континентальными осадочными сериями. Разрез Чадской синеклизы, в основании которой залегают породы меловой континентальной серии [30], в целом 
аналогичен разрезу Мали-Нигерской синеклизы. Северо-западная ветвь Чадской синеклизы - прогиб Тенере, выполнена континентальными и морскими отложениями мелового-раннетретичного возраста [29]. В южной части бассейна Мурзук, расположенного на северо-востоке региона, развиты терригенные континентальные толщи мезозоя и кайнозоя [31].

Приведённые краткие геологические сведения по региону использовались ниже при анализе результатов интерпретации гравиметрических данных.

\section{Исходные данные}

На территории Республики Нигер до настоящего времени не проводились сейсмические зондирования земной коры с контролируемыми источниками и поэтому все оценки мощности земной коры и литосферы получены в результате интерпретации региональных сейсмологических данных методами сейсмотомографии и анализа функции приёмника [21, 32]. Эти методы опираются на априорные данные и ограничения для скоростных моделей Земли $[11,12$, $33,34]$, в силу чего результаты сейсмических построений частично отражают различие исходных моделей и степень пространственного разрешения для скоростных структур коры, составляющую от $2^{\circ}$ до $5^{\circ}$. Томографические скоростные модели, построенные по данным о дисперсии поверхностных волн [13, 35], также опираются на стартовую модель LITHO1.0 с пространственной разрешимостью $1^{\circ}$.

Положение глубины границы подошвы земной коры для территории Республики Нигер определялось и по гравиметрическим данным [36-38]. Такие оценки мощности земной коры базируются на согласовании обобщённых сейсмологических моделей литосферы с данными спутниковых гравитационных аномалий в редукции Буге (EIGEN-6C, GOCE и EGM). Пространственная разрешимость построений соответствует исходным моделям, то есть не превышает (1-2) ${ }^{\circ}$ Ещё один подход к построению глубины границы Мохо основан на использовании деконволюции Эйлера [39] для интерпретации региональных гравитационных аномалий [40]. И хотя в этом исследовании заявлено пространственное разрешение в $0.25^{\circ}$, но достоверность полученных величин мощности коры остаётся под вопросом, что отмечается в [41].

Следует отметить, что выполненное в [21] сравнение приведённых выше моделей литосферы по всей территории Западной Африки демонстрирует значительные различия в результатах оценки мощности земной коры в районах, не обеспеченных сейсмическими данными, к которым и относится территория Республики Нигер. Здесь отличие в глубине положения границы Мохо, построенных в рамках разных методов и моделей исходных данных, достигают значений 20-25 км. Именно это обстоятельство диктует необходимость обратиться к проблеме гравитационного моделирования строения земной коры изучаемой территории, в качестве исходной модели которой мы выбрали модели CRUST1 [12] и
LITHO1.0 [13], отражающие с необходимой детальностью основные структурные ярусы литосферы.

Региональная съёмка гравитационного поля на территории Республики Нигер была выполнена в середине шестидесятых годов силами французских геофизиков [42]. Съёмка проводилась по системе неориентированных пересекающихся профилей с привязкой к системе опорных геодезических и гравиметрических пунктов. Всего было выполнено более 14500 наблюдений с точностью рядовых измерений поля примерно 0.1 мГал. Суммарная ошибка съёмки составляла не более 0.5 мГал, что позволило построить карту гравитационных аномалий в редукции Буге для изученной территории в масштабе 1:1 000000 с сечением изолиний в 1 мГал, на которой показаны также значения измерений в точках съёмки. Эти картографические материалы были использованы нами для создания цифровой модели аномального гравитационного поля территории Республики Нигер. Привязка данных наблюдений и их оцифровка выполнялась в системе ArcGIS (в координатах проекции гравиметрической карты [42]), что позволило составить сводный каталог точек наблюдений гравитационного поля в географических координатах.

Помимо данных наземных измерений, для всей территории исследований (см. рис. 1) нами использовалась спутниковая модель гравитационного поля в редукции Буге EGM2008 [10], рассчитанная на уровне рельефа в узлах регулярной пространственной сетки с разрешением $5^{\prime} \times 5^{\prime}$. Сопоставление данных модели поля EGM2008 с данными наземных наблюдений выполнялось средствами пространственного анализа в системе ArcGIS только для территории Республики Нигер. Рассматривались пары точек указанных цифровых моделей поля отстоящих друг от друга на расстояние не более 1 км. Статистика расхождения значений разности полей EGM2008 $\left(\Delta g_{\mathrm{EGM}}\right)$ и данных наземной съёмки $\left(\Delta g_{\mathrm{LD}}\right)$, приведённая на рис. 2 , демонстрирует небольшое различие средних уровней полей при общем расхождение для парных точек в диапазоне от -12 до 8 мГал со стандартным отклонением значений поля равным 3.40 мГал. Отметим, что максимальные различия полей пространственно приходятся на локальные области с высокими горизонтальными градиентами поля наземной съёмки, которые в плане совпадают с бортами грабенообразных структур в чехле и кристаллическом фундаменте [42, 43].

Таким образом, выявляемые локальные различия в полях во многом объясняются спецификой геологического строения территории и различием детальности пространственного разрешения данных спутниковой и наземной съёмок. В этой ситуации, учитывая, что основным объектом наших исследований является территория Республики Нигер, наиболее обоснованным представляется использование гравиметрических данных наземной съёмки [42] внутри и поля EGM2008 [10] во внешности этой территории. Такая сводная синтетическая модель гравитационного поля в 
редукции Буге, включающая данные наземной съёмки по нерегулярной системе точке и спутниковые наблюдения по регулярной географической сети, показанные на рис. 3, послужила основой при решении задач регионального гравиметрического моделирования. Построение цифровой модели поля выполнялось по сводной синтетической модели съёмок для регулярной сети с пространственным разрешением в 5 км. На стадии интерполяции сводных материалов съёмок в указанную регулярную плановую сетку, используемую в гравиметрическом моделировании, применялось гармоническое усреднение данных [2] в относительно узкой буферной зоне сопряжения съёмок, так чтобы на границах областей с разной

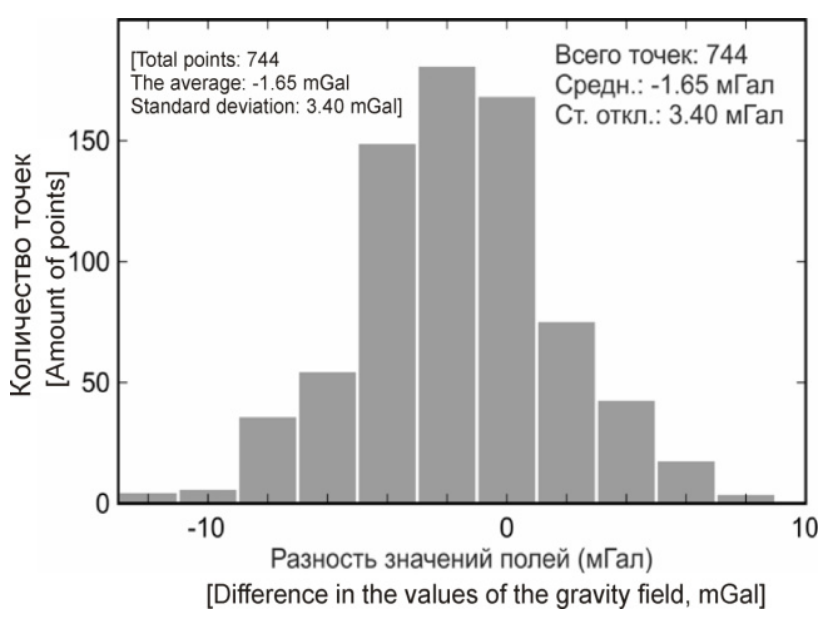

Рис. 2. Гистограмма оценки разности значений гравитационного поля в редукции Буге для парных точек: $\Delta g_{\mathrm{EGM}}-\Delta g_{\mathrm{LD}}$.

[Fig. 2. Histogram assesses the difference in the values of the gravity field in the Bouguer reduction for paired points: $\Delta g_{\mathrm{EGM}}$ $\left.-\Delta g_{\text {LD. }}\right]$

\section{Методика}

Аномальное гравитационное поле исследуемого региона отражает влияние всех плотностных неоднородностей литосферы, наиболее контрастными из которых является осадочный чехол и граница раздела кора-мантия. Учёт гравитационного влияния этих объектов, как это сделано в $[5,16]$, позволяет получить аномальное поле, обусловленное только внутрикоровыми плотностными неоднородностями региона. Отметим, что если мощность осадочных пород чехла достаточно подробно отражена в цифровых моделях CRUST1 и LITHO1.0 [12, 13], то глубина границы Мохо значительно отличается для разных моделей нашей территории как это показано в [21]. Таким образом, представляется необходимым выполнить ревизию данных по глубине залегания границы Мохо, используя иные технологии интерпретации, в частности, стохастическое оценивание параметров слоя со случайным распределением источников гравитацион- представительностью данных не возникало резкоградиентных скачков поля.

Территория Республики Нигер и прилегающих стран характеризуется существенно расчленённым рельефом, влияние которого обязательно должно приниматься во внимание при гравиметрическом моделировании. В качестве данных о высотах рельефа использовалась модель ЕТОРО1 [44], синтезированная для всей территории исследований в узлах регулярной пространственной сетки с разрешением $1 ' \times 1$ '. Имеющиеся данные о рельефе, демонстрируют основные топографические особенности региона с диапазоном изменений высот от 50 м до 3000 м, и естественно влияет на его аномальное гравитационное поле.

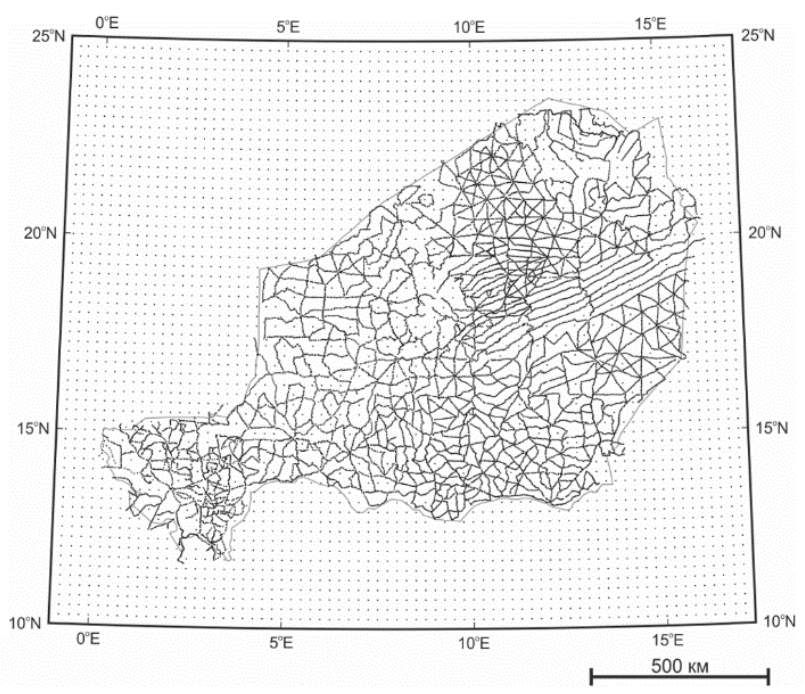

Рис. 3. Точки данных в сводной модели гравитационного поля (спутниковые данные EGM2008 показаны на разряженной сетке $15^{\prime} \times 15^{\prime}$ ).

[Fig. 3. Data points in the composite model of the gravity field (satellite data EGM2008 are shown on the discharged grid of $\left.15^{\prime} \times 15^{\prime}\right)$.]

ного поля [2, 9, 45].

В трёхмерном случае, для произвольного случайного изотропного распределения сингулярных источников в горизонтальном слое с некоторым симметричным некоррелированным распределением плотности, известно [2, 45] выражение нормированной автокорреляционной функции случайного гравитационного поля, порождаемой такой моделью. Указанное выражение имеет вид:

$$
B_{N}(\tau, h, H)=\frac{2 h H}{H-h}\left(\frac{1}{\sqrt{4 h^{2}+\tau^{2}}}-\frac{1}{\sqrt{4 H^{2}+\tau^{2}}}\right)
$$

где $h$ и $H$ - глубина до верхней и нижней границы слоя, a $\tau$ - аргумент корреляционной функции для среднего на окружности значения гравитационного поля.

Определение параметров модельного слоя $h$ и $H$, основано на использовании критерия минимума невязки (по норме в $L_{1}$ ) между наблюдённой и 
теоретической нормированной автокорреляционной функцией гравитационного поля [2, 9]. Величина невязки $\delta(h, H)$ даётся выражением:

$$
\delta(h, H)=\frac{1}{M} \sum_{m=1}^{M}\left|B_{N}^{o b s}\left(\tau_{m}\right)-B_{N}^{\bmod }\left(\tau_{m}, h, H\right)\right|
$$

где $B_{N}^{o b s}$ обозначает наблюденную функцию, а $B_{N}^{\text {mod }}$ теоретическую (модельную) автокорреляционную функцию. Число точек $M$, используемых для вычисления, должно лежать в интервале радиуса корреляции наблюдённого поля [2]. Отметим, что совместное определение $h$ и $H$ по критерию (2) является неустойчивым в силу принципа эквивалентности, но решение задачи можно стабилизировать, используя оценку глубины до верхней границы слоя $h$ и выполняя подбор только по параметру $H$.

Использование стохастической оценки мощности земной коры, основано на вычислении в скользящем окне размером 300 на 300 км двухмерной автокорреляционной функции гравитационного поля, интерполированного в правильную регулярную сеть с шагом по 5 км. Пример таких построений для одного участка сводной карты поля приведён на рис. 4, где показана вычисленная двухмерная нормированная автокорреляционная функция гравитационного поля и собственно оценки мощности земной коры по критерию (2). Разумеется, полученные результаты стохастической интерпретации следует рассматривать как приближённую оценку глубин верхней и нижней границ в рамках принятой модели.
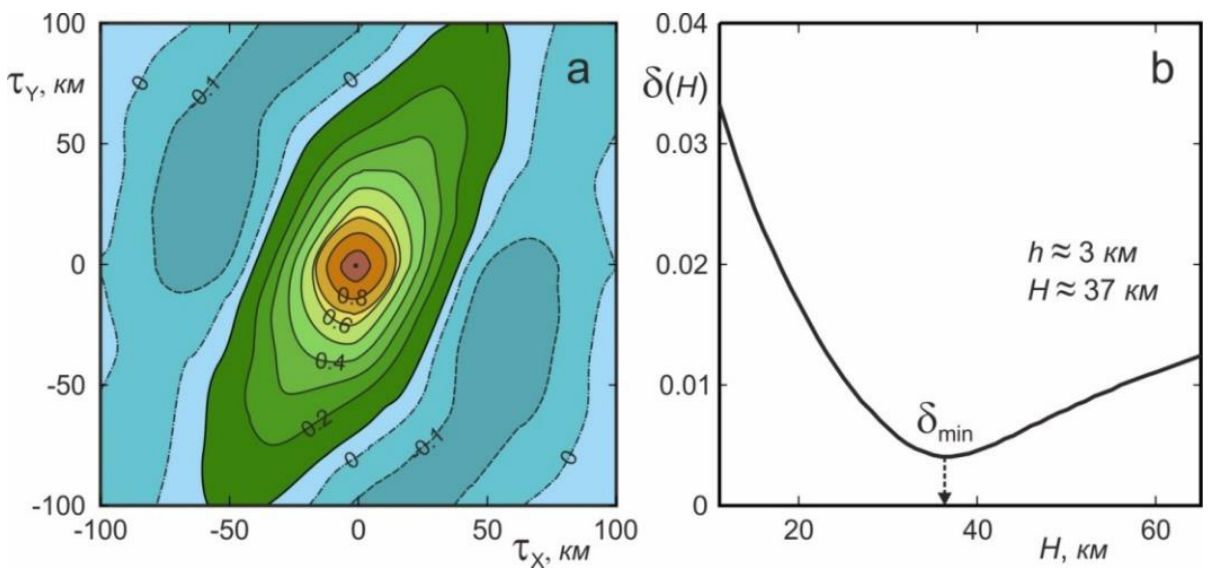

Рис. 4. Пример стохастической оценки мощности земной коры: а) двухмерная нормированная автокорреляционная функция гравитационного поля, рассчитанная в скользящем окне; b) вид сечения функционала невязки $\delta(H)$, позволяющий оценить глубину нижней границы слоя $-H$, при заданной величине его верхней границы $h$.

[Fig. 4. An example of a stochastic estimates of the thicknesses of the earth's crust: (a) a two-dimensional normalized autocorrelation function of the gravity field, calculated in a sliding window; (b) a type of cross-section function $\delta(H)$ to estimate the depth of the bottom boundary of the $H$ layer, at a given size of its upper limit $h$.]

По предложенной методике было обработано гравитационное поле территории исследований (с частичным выходом за границы выделенного участка) для 130 положений скользящего окна расчётов. Сдвиг положения скользящего окна составлял половину его ширины - 150 км. При относительно изотропном распределении поля вычисление усреднённой на окружности автокорреляционной функции, или одномерной проекции этой функции по направлению с минимальным радиусом корреляции, позволило получить содержательные оценки глубины границы Мохо в рамках принятой модели. Однако, в ряде случаев, рассчитанная двухмерная автокорреляционная функция демонстрировала значительную анизотропию исходного гравитационного поля в текущем окне, что не позволяет достоверно оценить мощность модельного слоя. При построении схемы мощности земной коры учитывалась усреднённая высота рельефа территории, вычисляемая в рамках площади текущего скользящего окна, по данным модели ЕТОРО1 [44].

В целом полученные новые данные использовались для создания сводной цифровой модели мощности земной коры и положения границы Мохо региона.

\section{Результаты и обсуждение}

Результаты стохастической интерпретации гравитационного поля были представлены в виде карты мощности земной коры для территории исследований и ближайших сопредельных к ней участков. Поскольку наши данные являются некоторой оценкой мощности земной коры, то построение изолиний глубин выполнялось с сечением равным 2 км. Итоговая схема мощности коры по данным стохастической интерпретации гравитационных аномалий приведена на рис. 5 только в пределах изучаемой территории. Эта схема, сопоставленная с данными о мощности земной коры для модели CRUST1 [12], демонстрирует значительные различия показанных моделей, особенно в восточной части нашего региона. Отметим, что в пределах территории исследований модель CRUST1 характеризуется наличием крупных элементов исходной сетки данных, унаследованных от первичного набора 
CRUST5 [11], то есть модель CRUST1 практически не повышает детализации строения коры по сравнению с первичной моделью CRUST5. На эту специфику модели CRUST1 ранее обращалось внимание в [21].

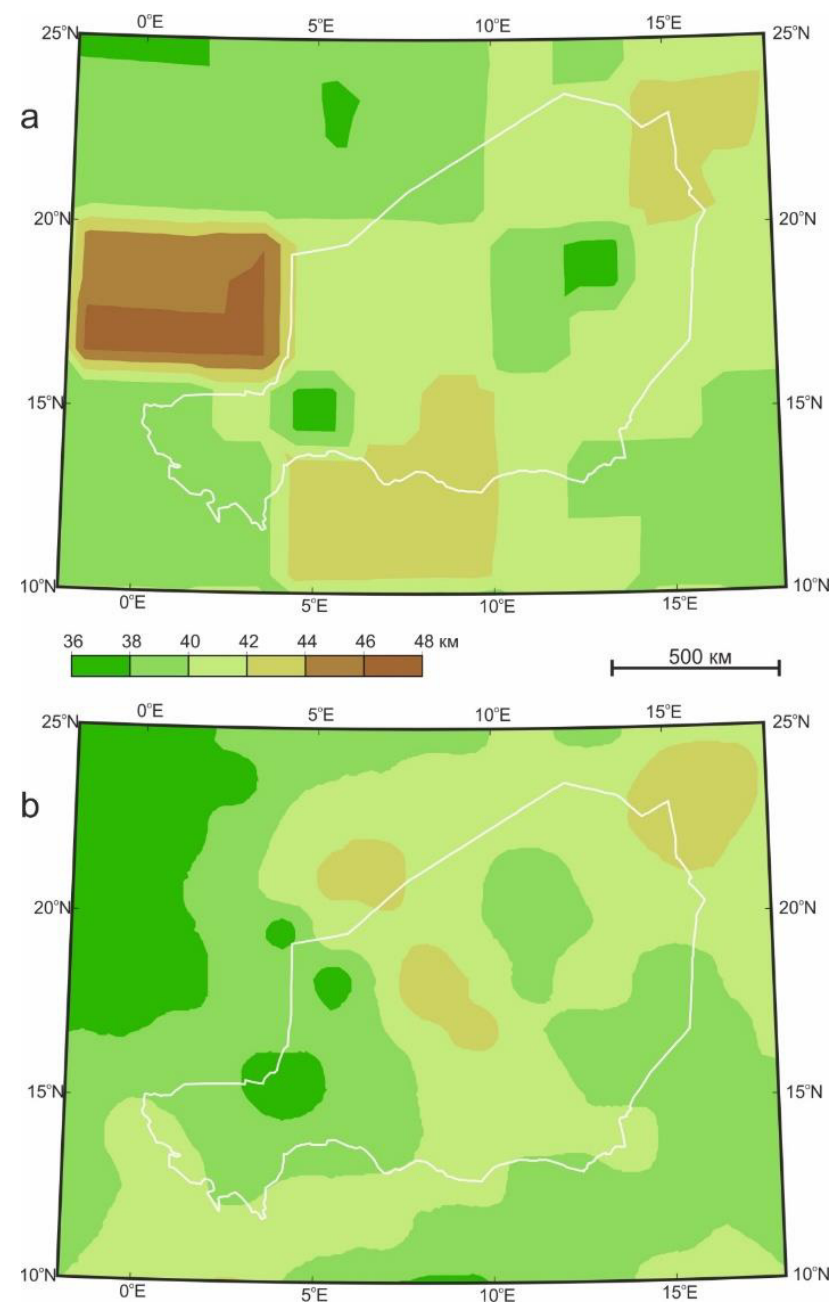

Рис. 5. Мощность земной коры: а) модель CRUST1 [12]; b) наши данные по результатам стохастической интерпретации гравитационного поля. Схемы приведены в единой цветовой шкале.

[Fig. 5. Estimates of the thickness of the earth's crust: (a) the CRUST1 model [12]; (b) our results of the stochastic interpretation of the gravity field. Schemes are given in a single color scale.]

Анализ различий приведённых моделей мощности коры, был выполнен только в тех точках, где имелась стохастическая оценка мощности по изложенной выше методике (всего использовано 70 точек данных в пределах нашей территории). Для корректного сравнения результатов мощность коры модели CRUST1 интерполировалась в точки, с известными стохастическими оценками. Статистика расхождения значений мощности земной коры по стохастической оценке и интерполированных данных модели CRUST1, приведённая на рис. 6 , демонстрирует незначительное различие средних величин мощности при общем расхождение моделей в диапазоне от -5 до 9 км со стандартным отклонением равным 3.04 км. При этом, экстремальные различия мощности коры пространственно приходятся на изометричную область с максимальной мощностью для модели CRUST1. Для остальных же частей расхождения моделей лежат в диапазоне стандартного отклонения разности мощностей коры.

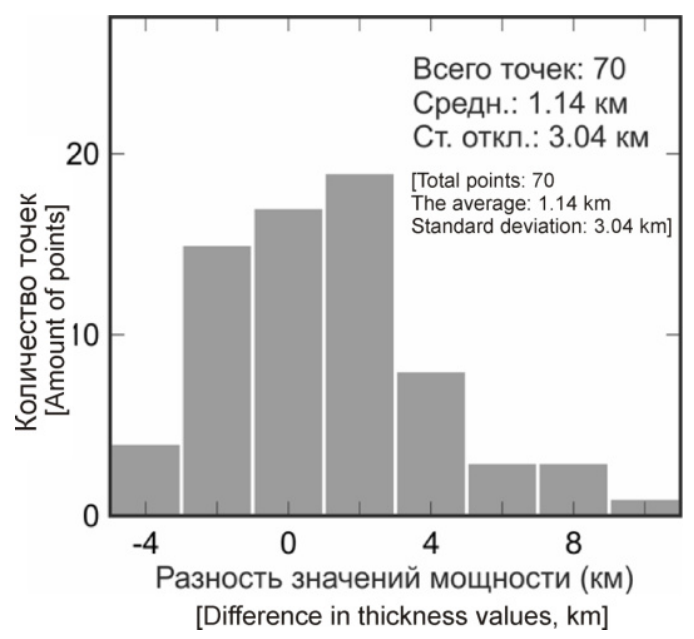

Рис. 6. Гистограмма разности значений мощности земной коры по стохастической оценке и модели CRUST1.

[Fig. 6. Histogram of the difference in thickness values of the earth's crust according to stochastic assessment and model CRUST1.]

Отметим, что по величинам значений мощности и общей морфологии границы раздела кора-мантия, наша модель в целом хорошо сходится с результатами моделирования [38], полученными с предельным пространственным разрешением $0.5^{\circ}$ на основе согласования модели коры CRUST2 и спутниковых гравитационных аномалий в редукции Буге (модель GOCE). Для высокоточной модели коры LITHO1.0 [13], пространственное разрешение которой достигает $0.16^{\circ}$, следует отметить, что по морфологии границы раздела кора-мантия эта модель подобна нашей, но характеризуется постоянным отклонением величины мощности на 5-7 км в большую сторону, по сравнению с нашими данными. Поскольку при построении указанных моделей использовались принципы изостатической компенсации гравитационного поля, целесообразно проанализировать аналогичные подходы и для нашей модели.

Такой анализ был выполнен для точек с полученными значениями стохастических оценок мощности земной коры и усреднённых величин рельефа модели ЕTOPO1 [44]. Усреднение величин высот рельефа осуществлялось в радиальной буферной зоне, радиусом 50 км вокруг каждой точки с данными о мощности коры. Сопоставление значений мощности земной коры по нашим оценкам и усреднённых высот рельефа региона показано на рис. 7. На диаграмме видно, что область точек корреляции параметров, хотя и имеет относительно большой разброс данных, но всё же образует устойчивую тенденцию связи между величинами. Линейное уравнение регрессии, приведённое на 
диаграмме вместе с значением достоверности аппроксимации, описывает соотношение между рассмотренными величинами. Таким образом, выявленная тенденция статистической связи мощности коры с усреднёнными величинами высот рельефа позволяет сделать вывод о частичной изостатической компенсации для крупных блоков коры, являющейся следствием геодинамической эволюции литосферы региона на самом последнем этапе её развития. Уровень и характер полноты изостатической компенсации заслуживает отдельного рассмотрения, с учётом ряда важных факторов, рассмотренных в [4, 46, 47].

Ещё одним аспектом нашей модели является возможный характер отражения геодинамических процессов в глубинном положении границы раздела корамантия. Такого рода качественный анализ позволяет связывать особенности проявления геодинамики литосферы региона с поведением крупных геофизических неоднородностей, как это сделано в [4, 14, 16, 17, 21 и др.]. Сопоставление региональной геологотектонической схемы территории Республики Нигер (рис. 1) и наших данных о мощности земной коры (рис. 5 b) позволяет наметить некоторые особенности литосферы в пределах региона исследований, показанные на рис. 8 в упрощённом виде.

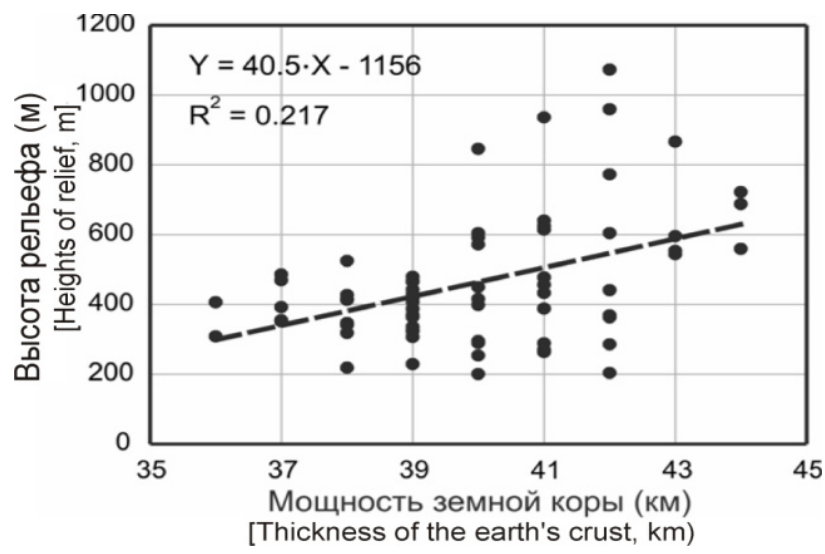

Рис. 7. Корреляция высот рельефа и мощности земной коры (показано уравнение линейной регрессии $\mathrm{Y}(\mathrm{X})$ и значение величины достоверности аппроксимации $\mathrm{R}^{2}$ ).

[Fig. 7. Correlation of the heights of relief and the thickness of the earth's crust (shown the equation of linear regression $\mathrm{Y}(\mathrm{X})$ and the value of the magnitude of the confidence of the $\mathrm{R}^{2}$ approximation).]

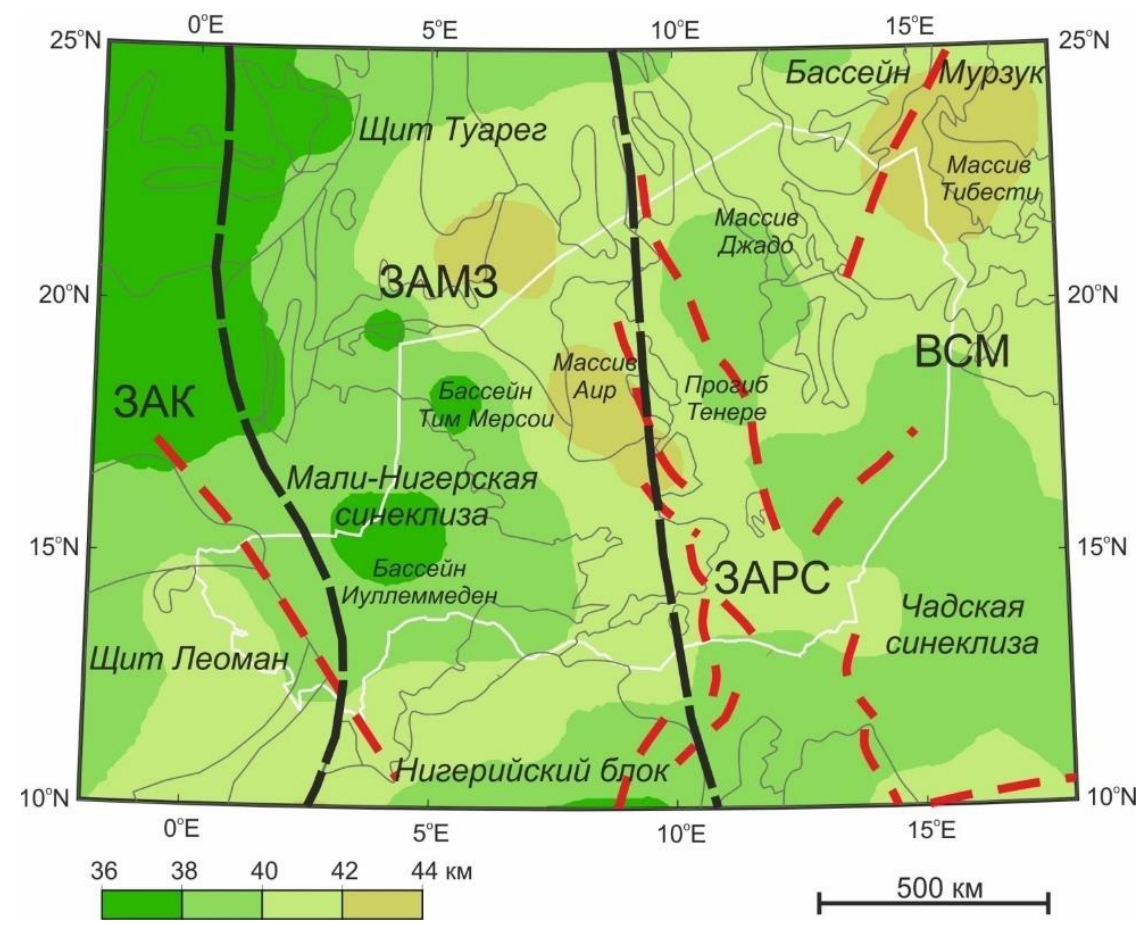

Рис. 8. Сопоставление геолого-структурной схемы и данных о мощности земной коры. Показаны границы геологических комплексов, согласно рис. 1. Условные обозначения и аббревиатуры см. рис. 1.

[Fig. 8. Comparison of geology-tectonic map and data on the thickness of the earth's crust. The boundaries of geological complexes are shown, according to fig. 1. Legend and abbreviations see fig. 1.]

1. Восточная граница Западно-Африканского кратона достаточно хорошо отождествляется с плавным “локальным" изменением мощности земной коры от 40-42 км до 36-38 км, что несколько отличается от выводов [13, 21, 32] о повсеместном увеличении мощности коры под кратоном до значений 40-45 км и даже более. Западная граница Восточно-Сахарского мегакратона почти не проявляется в характеристиках мощности земной коры нашего региона, что соответствует и данным из [32]. Тем не менее, меридиональная ориентировка структуры Западно-Африканской мобильной зоны, разделяющей эти литосферные кратоны, выражена в аналогичной ориентировке системы "локальных" поднятий и прогибов мощности 
земной коры вдоль мобильной зоны. То есть в пределах изучаемой территории область ЗАМЗ характеризуется как зона максимальных горизонтальных градиентов мощности земной коры, а предположение о тенденции повсеместного утонения земной коры в этой зоне до 35 км $[13,32]$ - верно лишь отчасти.

2. Граница раздела кора-мантия под архейскими и палеопротерозойскими щитами, представленными в регионе исследований: Туарег, Леоман и Нигерийский блок (щит) - в нашей модели характеризуется с различной степенью пространственного охвата и детальности. Для щита Туарег, вместе с крупными его фрагментами массивами Аир и Джадо, отмечается общая тенденция некоторого "локального" повышения мощности земной коры по сравнению с прилегающими блоками, что в целом совпадает с результатами построений $[32,38]$. Массив Тибести, ядро которого имеет архейский возраст, выделяется как изометричная область повышенной мощности земной коры до 44 км. Механизм становления указанных массивов на последнем этапе их эволюции, обусловленный магматическим подслаиванием коры [27], вполне отвечает нашим данным о суммарной мощности коры, понимаемой как латерально-неоднородная область в самой верхней части литосферы [4, 47]. Относительно мощности земной коры щита Леоман и Нигерийского блока выводы можно сделать только для краевых частей этих объектов, где по нашим оценкам мощность земной коры принимает среднее значение в 38-42 км. Указанные значения мощности совпадают с оценками [38], но отличаются от данных [12], где мощность коры предполагается на уровне 44- 48 км.

3. Мали-Нигерская синеклиза в наших данных проявляется как область с несколько пониженной мощностью земной коры до 38-40 км, на фоне которой существуют "локальные" зоны уменьшения мощности под бассейнами Иуллеммеден и Тим Мерсои. Эти оценки в целом хорошо согласуются с результатами $[21,38]$ и существенно противоречат данным для моделей $[12,13]$ с повышенной мощностью коры до 42-48 км. Область Чадской синеклизы характеризуется средним уровнем мощности земной коры 38-42 км, на фоне которой просматривается ориентировка собственно пониженной мощности коры субмеридианального простирания. Указанные величины мощности коры в целом согласуются с результатами [32], показывающими аналогичные значения. Мезозойская Западно-Африканская рифтовая система [29, 30] в наших данных проявлена как зона субмеридианального градиента мощности земной коры, без уменьшения её амплитуды до 32-36 км, предполагаемой по результатам интерпретации [32, 37].

\section{Выводы}

Представленные результаты регионального обобщения и интерпретации гравиметрических данных по территории Республики Нигер и прилегающих областей Западной Африки позволяют сформулировать следующие выводы.
1. Составленная синтетическая модель гравитационного поля в редукции Буге, включающая данные наземной съёмки и спутниковые наблюдения, может служить достоверной основой при решении задач регионального гравиметрического моделирования.

2. Результаты стохастической интерпретации гравитационного поля региона позволили получить содержательные оценки мощности земной коры изучаемой территории в рамках принятой модели слоя со случайным распределением плотностных неоднородностей.

3. Выполненное сопоставление полученных оценок мощности земной коры с данными стандартной модели CRUST1 демонстрирует существенные несоответствие последней для изучаемой территории.

4. Выявленная тенденция частичной изостатической компенсации крупных блоков коры свидетельствует о роли геодинамических процессов в формировании литосферы региона на последнем этапе её эволюции.

5. Анализ наших данных о мощности земной коры позволил наметить особенности глубинного строения блоков литосферы, отождествляемых с некоторыми крупными элементами геолого-тектонической схемы территории Республики Нигер.

Конфликт интересов. Авторы декларируют отсутствие явных и потенциальных конфликтов интересов, связанных с публикацией настоящей статьи.

\section{ЛИТЕРАТУРА}

1. Glaznev V. N., Raevsky A. B., Skopenko G. B. A threedimensional integrated density and thermal model of the Fennoscandian lithosphere // Tectonophysics. 1996. V. 258. № 1-4. P. 15-33. DOI: 10.1016/0040-1951(95)00147-6

2. Глазнев В. Н. Комплексные геофизические модели литосферы Фенноскандии. Апатиты, «КаэМ». 2003. 252 с.

3.Majdański M., Grad M., Kozlovskaya E. 3D structure of the earth's crust beneath the northern part of the Bohemian massif // Tectonophysics. 2007. V. 437. № 1-4. P. 17-36. DOI: 10.1016/j.tecto.2007.02.015

4. Glaznev V. N., Mints M. V., Muravina O. M., Raevsky A. B., Osipenko L. G. Complex geological-geophysical 3D model of the crust in the southeastern Fennoscandian Shield: Nature of density layering of the crust and crust-mantle boundary // Geodynamics \& Tectonophysics. 2015. V. 6. № 2. P. 133-170. DOI: 10.5800/GT2015-6-2-0176

5. Муравина О. М. Плотностная модель земной коры Воронежского кристаллического массива // Вестник Воронежского государственного университета. Серия: Геология. 2016. № 1. C. 108-114. URL: https://www.elibrary.ru/download/elibrary_25942779_54324014.pdf (дата обращения: 19.11.2020)

6. Motavalli-Änbaran S. H., Zeyen H., Jamasb A. 3D crustal and lithospheric model of the Arabia - Eurasia collision zone // Journal of Asian Earth Sciences. 2016. V. 122. P. 158-167. DOI: 10.1016/j.jseaes.2016.03.012

7. Буянов А. Ф., Глазнев В. Н., Раевский А. Б., Скопенко Г. Б. Комплексная интерпретация данных гравиметрии, сейсмометрии и геотермии // Геофизический журнал. 1989. Т. 11. № 2. С. 30-39.

8. Glaznev V. N., Raevsky A. B., Sharov N. V. A model of the deep structure of the north-eastern part of the Baltic Shield based on joint interpretation of seismic, gravity, magnetic and heat $\mathrm{f}$ low data // Tectonophysics. 1989. V. 162. № 1-2. P. 151-164. DOI: 10.1016/0040-1951(89)90361-2 
9. Глазнев В. Н., Муравина О. М., Воронова Т. А., Холин В. М Оценка мощности гравиактивного слоя земной коры Воронежского кристаллического массива // Вестник Воронежского государственного университета. Серия: Геология. 2014. № 4. C. $78-84$.

URL:

https://www.elibrary.ru/download/elibrary_22821537_89298989.pd $\mathrm{f}$ (дата обращения: 19.11.2020)

10. Pavlis N. K., Holmes S. A., Kenyon S. C., Factor J. K. The development and evaluation of the Earth Gravitational Model 2008 (EGM2008) // Journal Geophysical Research, Solid Earth. 2012. V. 117. B04406. DOI: 10.1029/2011JB008916

11. Mooney W., Laske G., Masters G. CRUST 5.1 : A global crustal model at 5x5 degrees // Journal Geophysical Research. 1998. V. 103. P. 727-747. DOI: 10.1029/97JB02122

12. Laske G., Masters G., Ma Z., Pasyanos M. Update on CRUST1.0 - A 1-degree Global Model of Earth's Crust // Abstract EGU20132658 presented at 2013 Geophys. Res. Abstracts. 2013. 15. EGU2013-2658.

13. Pasyanos M. E., Masters G., Laske G., Ma Z. LITHO1.0 : An updated crust and lithospheric model of the Earth // Journal Geophysical Research. Solid Earth. 2014. V. 119. P. 2153-2173. DOI: 10.1002/2013JB010626

14. Mitrofanov F. P., Sharov N. V., Zagorodny V. G., Glaznev V. N., Korja A. Crustal structure of the Baltic shield along the Pechenga Kostomuksha - Lovisa geotraverse // International Geology Review. 1998. V. 40. № 11. P. 990-997. DOI: 10.1080/0020681980946 15. Арзамасцев А. А, Арзамасцева Л. В., Жирова А. М., Глазнев В. Н. Модель формирования Хибино-Ловозерского рудоносного вулкано-плутонического комплекса // Геология рудных месторождений. 2013. Т. 55. № 5. C. 397-414. URL: https://www.elibrary.ru/download/elibrary_20301086_30101907.pd $\mathrm{f}$ (дата обращения: 19.11.2020)

16. Глазнев В. Н., Минц М. В., Муравина О. М. Плотностное моделирование земной коры центральной части ВосточноЕвропейской платформы // Вестник КРАУНЦ. Сер.: Науки о Земле. 2016. № 1 (29). С. 53-63. URL: http://www.kscnet.ru/journal/kraesc/article/viewFile/69/pdf (дата обращения: 19.11.2020)

17. Минц М. В., Глазнев В. Н., Муравина О.М. Глубинное строение коры юго-востока Воронежского кристаллического массива по геофизическим данным: геодинамическая эволюция в палеопротерозое и современное состояние коры // Вестник Воронежского государственного университета. Серия: Геология. 2017. № 4. C. 5-23. URL: http://www.vestnik.vsu.ru/pdf/heologia/2017/04/2017-04-01.pdf (дата обращения: 19.11.2020)

18. Schluter T. Geological Atlas of Africa / Berlin. Springer. 2nd ed., 2008. 318 p. ISBN: 978-3-540-76324-6

19. Thieblemont D. (Ed.) et. al. Geological Map of Africa at 1:10M scale / CGMW-BRGM. South Africa. Cape Town. 2016. DOI: 10.14682/2016GEOAFR

20. Begg G. C., Griffin W. L., Natapov L. M., O'Reilly S. Y., Grand S. P., O'Neill C. J., Hronsky J.M.A., Djomani Y. P., Swain C. J., Deen T., Bowden P. The lithospheric architecture of Africa: seismic tomography, mantle petrology and tectonic evolution // Geosphere. 2009. V. 5. № 1. P. $23-50$. DOI: $10.1130 /$ GES00179.1

21. Jessell M. W., Begg G. C., Miller M. S. The Geophysical Signatures of the West African Craton // Precambrian Research 2016. V. 274. № 3. P. 3-24. DOI: 10.1016/j.precamres.2015.08.010 22. Liégeois J. P., Benhallou A., Azzouni-Sekkal A., Yahiaoui R., Bonin B. The Hoggar swell and volcanism : Reactivation of the Precambrian Tuareg shield during Alpine convergence and West African Cenozoic volcanism / Plates, plumes, and paradigms. Eds: Foulger G.R., Natland J.H., Anderson D.L. Geological Society of America, Special Paper. 2005. P. 379-400. DOI: 10.1130/0-81372388-4.379

23. Black R., Liégeois J.P. Cratons, mobile belts, alkaline rocks and continental lithospheric mantle: The Pan-African testimony // Geological Society of London Journal. 1993. V. 150. P. 89-98. DOI: 10.1144/gsjgs.150.1.0088

24. Fezaa N, Liégeois JP, Abdallah N, Cherfouh EH, De Waele B,
Bruguier O, Ouabadi A. Late Ediacaran geological evolution (575$555 \mathrm{Ma}$ ) of the Djanet Terrane, Eastern Hoggar, Algeria, evidence for a Murzukian intracontinental episode // Precambrian Research. 2010. V. 180. P. 299-327. DOI: 10.1016/j.precamres.2010.05.011

25. Hugot G. A la recherche du Gondwana perdu aux origins du monde / France. Univ. Moutnpellier. 2004. 311 p. ISBN 2-84269$551-8$

26. Soumaila A., Henry P., Garba Z., Rossi M. REE patterns, Nd-Sm and $\mathrm{U}-\mathrm{Pb}$ ages of the metamorphic rocks of the Diagorou-Darbani greenstone belt (Liptako, SW Niger): implication for Birimian (Palaeoproterozoic) crustal genesis // Geological Society London, Special Publications. 2008. V. 297. P. 19-32. DOI: 10.1144/SP297.2 27. Permenter J. P., Oppenheimer C. Volcanoes of the Tibesti massif (Chad, northern Africa) // Bulletin Volcanology. 2007. V. 69. P. 609626. DOI: 10.1007/s00445-006-0098-x

28. Clermonté J., Yahaya M., Lang J., Oumarou J. Un bassin paléozoïque et mésozoïque en décrochement : le Tim Mersoï dans la région d'Arlit, à l'Ouest de l'Aïr (Niger) // Comptes rendus de l'Académie des sciences. Série 2. 1991. T. 312. P. 1189-1195.

29. Guiraud R., Bellion Y., Benkhelil J., Moreau C. Post Hercynian tectonics in northern and western Africa // Geological Journal. 1987. V. 22. P. 433-466. DOI: $10.1002 / \mathrm{gj} .3350220628$

30. Guiraud R., Maurin J.C. Early Cretaceous rifts of Western and Central Africa: an overview // Tectonophysics. 1992. V. 213. P. 153168. DOI: 10.1016/0040-1951(92)90256-6

31. Davidson L., Beswetherick S., Craig J., Eales M., Fisher A. The structure, stratigraphy and petroleum geology of the Murzuq Basin, southwest Libya // In: D. Worsley, M.A. Sola (Eds.). Geological Exploration in the Murzuq Basin. Elsevier Science. 2000. P. 295320. DOI: $10.1134 /$ S0016702914060032

32. Globig J., Fernandez M., Torne M., Verges J., Robert A., Faccenna $\mathrm{C}$. New insights into the crust and lithospheric mantle structure of Africa from elevation, geoid, and thermal analysis // Journal Geophysical Research. Solid Earth. 2016. V. 121. P. 53895424. DOI: $10.1002 / 2016 J$ B012972

33. Nataf H. C., Ricard Y. 3SMAC: An a priori tomographic model of the upper mantle based on geophysical modeling // Physics of the Earth and Planetary Interiors. 1996. V. 95. P. 101-122. DOI: 10.1016/0031-9201(95)03105-7

34. Bassin C., Laske G., Masters G. The current limits of resolution for surface wave tomography in North America // Eos Transaction $A G U$. 2000. V. 81. F897. DOI: 10.1007/s11589-007-0359-6

35. Pasyanos M. E., Nyblade A. A. A top to bottom lithospheric study of Africa and Arabia // Tectonophysics. 2007. V. 444. P. 27-44. DOI: 10.1016/j.tecto.2007.07.008

36. Bagherbandi M., Sjoberg L.E. Modelling the density contrast and depth of the Moho discontinuity by seismic and gravimetric-isostatic methods with an application to Africa // Journal of African Earth Sciences. 2012. V. 68. P. 111-120. DOI: 10.1016/j.jafrearsci.2012.04.003

37. Tugume F., Nyblade A., Julia J., Van der Meijde M. Precambrian crustal structure in Africa and Arabia: Evidence lacking for secular variation // Tectonophysics. 2013. V. 609. P. 250-266. DOI: $10.1016 /$ j.tecto.2013.04.027

38. Reguzzoni M., Sampietro D., Sanso F. Global Moho from the combination of the CRUST2.0 model and GOCE data // Geophysical Journal International. 2013. V 195(1). P. 222-237. DOI: $10.1093 / \mathrm{gji} / \mathrm{ggt} 247$

39. Thompson D.T. EULDPH: a new technique for making computer-assisted depth estimates from magnetic data // Geophysics. 1982. V. 47. P. 31-37. DOI: $10.1190 / 1.1441278$

40. Tedla G. E., van der Meijde M., Nyblade A. A., van der Meer F. D. A crustal thickness map of Africa derived from a global gravity field model using Euler deconvolution // Geophysical Journal International. 2011. V. 18 . P. 1-9. DOI: 10.1111/j.1365246X.2011.05140.x

41. Reid A. B., Ebbing J., Webb S. J. Comment on "A crustal thickness map of Africa derived from a global gravity field model using Euler deconvolution" by Getachev E. Tedla, M. van der Meijde, A.A. Nyblade and F.D. van der Meer // Geophysical Journal 
International. 2012. V. 189. P. 1217-1222. DOI: 10.1111/j.1365246X.2012.05353.x

42. Rechenmann J., Louis P. Mesure gravimetriques dans le Niger orienta. Années 1963 - 1964 - 1965 / Rapport Office de la Recherche Scientifique et Technique Outre-Mer. Paris. 1966.83 p.

43. Louis P., Rechenmann J. Interpretation geologique de certaines anomalies gravimetriques du Tenere (Republique du Niger) // Comptes rendus de l'Académie des sciences, Serie D. 1966. T. 263. P. 476-479.

44. Amante C., Eakins B.W. ETOPO1 - 1 Arc-Minute Global Relief Model: Procedures, Data Sources and Analysis // NOAA Technical Memorandum NESDIS NGDC-24. National Geophysical Data Center, NOAA. 2009. DOI: 10.7289/V5C8276M

45. Глазнев В. Н., Павловский В. И., Раевский А. Б. Автокорреляционные функции потенциальных полей, обусловленных горизонтальным слоем со случайным расположением источников // Физика Земли. 1978. № 8. С. 85-90.

46. Muravina O. M., Glaznev V. N., Zhavoronkin V. I., Mints M. V. Reflection of the Petrophysical Basement Rocks Models in Geophysical Fields / Eds.: Nurgaliev D, Khairullina N.. Springer Proceedings in Earth and Environmental Sciences: Practical and Theoretical Aspects of Geological Interpretation of Gravitational, Magnetic and Electric Fields. Springer Nature Switzerland AG, 2019. P. 49-54. DOI: 10.1007/978-3-319-97670-9

47. Mints M. V., Glaznev V. N., Muravina O. M., Sokolova E. Yu. 3D model of Svecofennian Accretionary Orogen and Karelia Craton based on geology, reflection seismics, magnetotellurics and density modelling: Geodynamic speculations // Geoscience Frontiers. 2020. V. 11 . № 3. P. 999-1023. DOI: 10.1016/j.gsf.2019.10.003

\title{
GEOPHYSICS
}

UDC 550.831.015.072

DOI: https://doi.org/10.17308/geology.2020.4/3126

ISSN 1609-0691

Received: 20.11 .2020

Accepted: 01.12.2020

Published online: 18.12 .2020

\section{Determining the thickness of the Earth's crust in the territory of the Republic of the Niger based on the stochastic interpretation of the gravitational field}

\author{
(c) 2020 V. N. Glaznev ${ }^{1,2}$, I. A. Yacouba ${ }^{1 凶}$ \\ ${ }^{1}$ Voronezh State University, 1 Universitetskaya pl., Voronezh 394018, Russian Federation \\ ${ }^{2}$ Geological Institute of the Kola Science Centre of the Russian Academy of Sciences, \\ 14 Fersmana ul., Apatity 184209, Russian Federation
}

\begin{abstract}
Introduction: The territory of the Republic of the Niger and the surrounding countries of West Africa are among the areas where few ground and aero-geophysical surveys have been conducted aimed at studying the Earth's crust in the region. The purpose of this article is to compile ground and satellite data regarding the gravitational field in order to study the Earth's crust based on incomplete geological and geophysical information. The aim of the subsequent interpretation of the detected gravity anomalies is to create an updated map of the thickness of the Earth's crust on the territory of the Republic of the Niger. At the moment, there are several significantly different versions of the crust structure in this area. Methodology: We combined the results of ground gravimetric surveys conducted in the 1960s and the modern digital satellite models of the gravitational field in order to produce a synthetic model of an anomalous field, which can be subsequently interpreted using a common stochastic model with singular sources distributed in the horizontal layer. Results and discussion: We used the results of the interpretation of gravity anomalies based on the stochastic model of the filed sources to make a map of the estimates of the thickness of the Earth's crust for the studied territory and its adjacent regions. The comparison of the produced map with the results of the previous studies of the thickness of the earth's crust, revealed significant difference in the models of the crust, especially in the eastern part of the region. The statistical analysis of the received estimates of the thickness of the Earth's crust and the averages of the terrain shows that these parameters tend to be connected. This indicates partial isostatic compensation for large blocks of the region's crust. The analysis of the thickness of the Earth's crust and the map of the surface geological and tectonic elements on the territory of the Republic of the Niger allowed us to determine the connection between the geodynamic evolution of the crust and the location of the crust-mantle boundary.

Conclusions: The synthetic model of the gravitational field reduced to the Bouguer anomaly serves as a reliable basis for solving the problems of regional gravimetric modelling. Based on the results of the stochastic interpretation of the
\end{abstract}

The content is available under Creative Commons Attribution 4.0 License.

\footnotetext{
$\bowtie$ Yacouba Ibrahim Abdou, e-mail: yibrahimabdou@yahoo.fr
} 
gravitational field of the region we obtained estimates of the thickness of the earth's crust of the studied territory within the accepted model of the layer with random distribution of density heterogeneities. Comparison of the obtained estimates of the thickness of the Earth's crust with the data of the standard crustal model CRUST1 demonstrates significant discrepancies with regard to the studied area. The analysis of new data on the thickness of the Earth's crust allowed us to identify the features of the deep structure of the lithospheric blocks associated with the large elements of the tectonic scheme of the territory of the Republic of the Niger.

Keywords: Republic of the Niger, gravitational field, stochastic interpretation, thickness of the Earth's crust.

For citation: Glaznev V. N., Yacouba I. A. Determining the thickness of the Earth's crust in the territory of the Republic of the Niger based on the stochastic interpretation of the gravitational field. Vestnik Voronezhskogo gosudarstvennogo universiteta. Seriya: Geologiya = Proceedings of Voronezh State University. Series: Geology, 2020, no. 4, pp. 46-58. DOI: https://doi.org/10.17308/geology.2020.4/3126

Conflict of interests: The authors declare the absence of obvious and potential conflicts of interest related to the publication of this article.

\section{REFERENCES}

1. Glaznev V. N., Raevsky A. B., Skopenko G. B. A threedimensional integrated density and thermal model of the Fennoscandian lithosphere. Tectonophysics, 1996, v. 258, no 1-4, pp. 15-33. DOI: 10.1016/0040-1951(95)00147-6

2. Glaznev V. N. Complexnyi geophysichesky modeli litosphery Fennoscandii [Complex geophysical models of the Fennoscandian lithosphere]. Apatity, «K\&M». 2003.252 p. (accessed: 19.11.2020). (in Russ.)

3. Majdański M., Grad M., Kozlovskaya E. 3D structure of the earth's crust beneath the northern part of the Bohemian massif Tectonophysics, 2007 , v. 437 , no $1-4$, pp. 17-36. DOI: 10.1016/j.tecto.2007.02.015

4. Glaznev V. N., Mints M. V., Muravina O. M., Raevsky A. B., Osipenko L. G. Complex geological-geophysical 3D model of the crust in the southeastern Fennoscandian Shield: Nature of density layering of the crust and crust-mantle boundary. Geodynamics \& Tectonophysics, 2015, v. 6, no. 2, pp. 133-170. DOI: 10.5800/GT-2015-6-2-0176

5. Muravina O. M. Density model of the Earth's crust of the Voronezh crystal massif. Vestnik Voronezhskogo gosudarstvennogo universiteta. Seriya: Geologiya $=$ Proceedings of Voronezh State University. Series: Geology, 2016, no. 1, pp. 108-114. URL: https://www.elibrary.ru/download/elibrary 25942779 54324014.pdf (accessed: 19.11.2020). (in Russ.)

6. Motavalli-Anbaran S. H., Zeyen H., Jamasb A. 3D crustal and lithospheric model of the Arabia - Eurasia collision zone. Journal of Asian Earth Sciences, 2016, v. 122, pp. 158-167. DOI: 10.1016/j.jseaes.2016.03.012

7. Buyanov A. F., Glaznev V. N., Raevskiy A. B., Scopenko G. B. Complexnay interpretacija dannuh gravimetrii, seismometrii I geotermii [Complex interpretation of gravimetry, seismometry and geothermal data]. Geofizicheskiy zurnal, 1989, v. 11, no. 2, pp. 30-39. (in Russ.)

8. Glaznev V. N., Raevsky A. B., Sharov N. V. A model of the deep structure of the north-eastern part of the Baltic Shield based on joint interpretation of seismic, gravity, magnetic and heat $\mathrm{f}$ low data. Tectonophysics, 1989 , v. 162 , no. 1-2, pp. 151-164. DOI: 10.1016/0040-1951(89)90361-2

9. Glaznev V. N., Muravina O. M., Voronova T. A., Holin V. M. Otshenka moshtnosti raviactivnogo sloay ztmnoy cory Voronezhskogo kristallicheskogo massiva [Assessment of the graviactive layer of the Earth's crust of the Voronezh crystalline massive]. Vestnik Voronezhskogo gosudarstvennogo universiteta. Seriya: Geologiya = Proceedings of Voronezh State University. Series: Geology, 2014, no. 4, pp. 78-84. URL: https://www.elibrary.ru/download/elibrary_22821537_89298989.pdf (accessed: 19.11.2020). (in Russ.)

10. Pavlis N. K., Holmes S. A., Kenyon S. C., Factor J. K. The development and evaluation of the Earth Gravitational Model 2008 (EGM2008). Journal Geophysical Research, Solid Earth, 2012, v. 117, B04406. DOI: 10.1029/2011JB008916

11. Mooney W., Laske G., Masters G. CRUST 5.1 : A global crustal model at 5x5 degrees. Journal Geophysical Research, 1998, v. 103 , pp. 727-747. DOI: 10.1029/97JB02122
12. Laske G., Masters G., Ma Z., Pasyanos M. Update on CRUST1.0 - A 1-degree Global Model of Earth's Crust. Abstract EGU2013-2658 presented at 2013 Geophys. Res. Abstracts, 2013, 15, EGU2013-2658. 13. Pasyanos M. E., Masters G., Laske G., Ma Z. LITHO1.0 : An updated crust and lithospheric model of the Earth. Journal Geophysical Research, Solid Earth, 2014, v. 119, pp. 2153-2173. DOI: 10.1002/2013JB010626

14. Mitrofanov F. P., Sharov N. V., Zagorodny V. G., Glaznev V. N., Korja A. Crustal structure of the Baltic shield along the Pechenga - Kostomuksha - Lovisa geotraverse. International Geology Review, 1998, v. 40, no 11, pp. 990-997. DOI: 10.1080/0020681980946

15. Arzamastsev A. A., Arzamastseva L. V., Zhirova A. M., Glaznev V. N. Model of formation of the Khibiny-Lovozero orebearing volcanic-plutonic complex. Geology of Ore Deposits, 2013 , v. 55, no. 5, pp. 341-356. DOI: 10.1134/S1075701513050024

16. Glaznev V. N., Mints M. V., Muravina O. M. Plotnostnoe modelirovanie zemnoy cory chentalnoq tchasti VostochnoEvropeiskoy platformy [Density modeling of the earth's crust of the central part of the Eastern European platform. Vestnik KRAUNTs. Ser.: Nauki o Zemle $=$ The KRAUNZ Herald. Ser.: Earth Sciences, 2016, no. 1 (29), pp. 53-63. URL: http://www.kscnet.ru/journal/kraesc/article/viewFile/69/pdf (accessed: 19.11.2020). (in Russ.)

17. Mints M. V., Glaznev V. N., Muravina O. M. Deep structure of the southeast Voronezh crystal massif according to geophysical data: geodynamic evolution in the paleoproterozoic and modern state of the crust. Vestnik Voronezhskogo gosudarstvennogo universiteta. Seriya: Geologiya $=$ Proceedings of Voronezh State University. Series: Geology, 2017, no. 4, pp. 5-23. URL: http://www.vestnik.vsu.ru/pdf/heologia/2017/04/2017-04-01.pdf (accessed: 19.11.2020). (in Russ., abstract in Eng.).

18. Schluter T. Geological Atlas of Africa. Berlin. Springer. 2nd ed., 2008. 318 p. ISBN: 978-3-540-76324-6

19. Thieblemont D. (Ed.) et. al. Geological Map of Africa at 1:10M scale. CGMW-BRGM. South Africa. Cape Town. 2016. DOI 10.14682/2016GEOAFR

20. Begg G. C., Griffin W. L., Natapov L. M., O'Reilly S. Y., Grand S. P., O'Neill C. J., Hronsky J.M.A., Djomani Y. P., Swain C. J., Deen T., Bowden P. The lithospheric architecture of Africa: seismic tomography, mantle petrology and tectonic evolution. Geosphere, 2009 , vol. 5, no. 1 , pp. 23-50. DOI: 10.1130/GES00179.1

21. Jessell M. W., Begg G. C., Miller M. S. The Geophysical Signatures of the West African Craton. Precambrian Research, 2016 v. 274 , no. 3, pp. 3-24. DOI: 10.1016/j.precamres.2015.08.010

22. Liégeois J. P., Benhallou A., Azzouni-Sekkal A., Yahiaoui R., Bonin B. The Hoggar swell and volcanism : Reactivation of the Precambrian Tuareg shield during Alpine convergence and West African Cenozoic volcanism. Plates, plumes, and paradigms. Eds: Foulger G.R., Natland J.H., Anderson D.L. Geological Society of America, Special Paper, 2005, pp. 379-400. DOI: 10.1130/0-8137-2388-4.379

23. Black R., Liégeois J. P. Cratons, mobile belts, alkaline rocks and continental lithospheric mantle: The Pan-African testimony. Geological Society of London Journal, 1993, vol. 150, pp. 89-98. DOI: 10.1144 /gsjgs.150.1.0088 
24. Fezaa N, Liégeois J.P, Abdallah N, Cherfouh E.H, De Waele B, Bruguier O, Ouabadi A. Late Ediacaran geological evolution (575-555 $\mathrm{Ma})$ of the Djanet Terrane, Eastern Hoggar, Algeria, evidence for a Murzukian intracontinental episode. Precambrian Research, 2010, vol. 180, pp. 299-327. DOI: 10.1016/j.precamres.2010.05.011

25. Hugot G. A la recherche du Gondwana perdu aux origins du monde. France. Univ. Moutnpellier. 2004, 311 p. ISBN 2-84269-551-8 26. Soumaila A., Henry P., Garba Z., Rossi M. REE patterns, Nd-Sm and $\mathrm{U}-\mathrm{Pb}$ ages of the metamorphic rocks of the Diagorou-Darban greenstone belt (Liptako, SW Niger): implication for Birimian (Palaeoproterozoic) crustal genesis. Geological Society London, Special Publications, 2008, vol. 297, pp. 19-32. DOI: 10.1144/SP297.2

27. Permenter J. P., Oppenheimer C. Volcanoes of the Tibesti massif (Chad, northern Africa). Bulletin Volcanology, 2007, v, 69, pp. 609626. DOI: 10.1007/s00445-006-0098-x

28. Clermonté J., Yahaya M., Lang J., Oumarou J. Un bassin paléozoïque et mésozoïque en décrochement : le Tim Mersoï dans la région d'Arlit, à l'Ouest de l'Aïr (Niger). Comptes rendus de l'Académie des sciences. Série 2, 1991, t. 312, pp. 1189-1195

29. Guiraud R., Bellion Y., Benkhelil J., Moreau C. Post Hercynian tectonics in northern and western Africa. Geological Journal, 1987, vol. 22, pp. 433-466. DOI: $10.1002 /$ gj.3350220628

30. Guiraud R., Maurin J.C. Early Cretaceous rifts of Western and Central Africa: an overview. Tectonophysics, 1992, vol. 213, pp. 153168. DOI: 10.1016/0040-1951(92)90256-6

31. Davidson L., Beswetherick S., Craig J., Eales M., Fisher A. et al. The structure, stratigraphy and petroleum geology of the Murzuq Basin, southwest Libya. Eds: D. Worsley, M.A. Sola. Geological Exploration in the Murzuq Basin. Elsevier Science, 2000, pp. 295-320. DOI: 10.1134/S0016702914060032

32. Globig J., Fernandez M., Torne M., Verges J., Robert A., Faccenna C. New insights into the crust and lithospheric mantle structure of Africa from elevation, geoid, and thermal analysis. Journal Geophysical Research. Solid Earth, 2016, vol. 121, pp. 5389-5424. DOI: $10.1002 / 2016 J B 012972$

33. Nataf H.C., Ricard Y. 3SMAC: An a priori tomographic model of the upper mantle based on geophysical modeling. Physics of the Earth and Planetary Interiors, 1996, vol. 95, pp. 101-122. DOI: 10.1016/0031-9201(95)03105-7

34. Bassin C., Laske G., Masters G. The current limits of resolution for surface wave tomography in North America. Eos Transaction AGU, 2000, vol. 81, F897. DOI: 10.1007/s11589-007-0359-6

35. Pasyanos M.E., Nyblade A.A. A top to bottom lithospheric study of Africa and Arabia. Tectonophysics, 2007, vol. 444, pp. 27-44. DOI: 10.1016/j.tecto.2007.07.008

36. Bagherbandi M., Sjoberg L.E. Modelling the density contrast and depth of the Moho discontinuity by seismic and gravimetric-isostatic methods with an application to Africa. Journal of African Earth Sciences, 2012, vol. 68, pp. 111-120. DOI: 10.1016/j.jafrearsci.2012.04.003
37. Tugume F., Nyblade A., Julia J., Van der Meijde M. Precambrian crustal structure in Africa and Arabia: Evidence lacking for secular variation. Tectonophysics, 2013, vol. 609, pp. 250-266. DOI: 10.1016/j.tecto.2013.04.027

38. Reguzzoni M., Sampietro D., Sanso F. Global Moho from the combination of the CRUST2.0 model and GOCE data. Geophysical Journal International, 2013, vol. 195, no. 1, pp.222-237. DOI: $10.1093 /$ gji $/$ ggt247

39. Thompson D. T. EULDPH: a new technique for making computer-assisted depth estimates from magnetic data. Geophysics, 1982, vol. 47, pp. 31-37. DOI: 10.1190/1.1441278

40. Tedla G.E., van der Meijde M., Nyblade A. A., van der Meer F.D. A crustal thickness map of Africa derived from a global gravity field model using Euler deconvolution. Geophysical Journal International, 2011, vol. 18, pp. 1-9. DOI: 10.1111/j.1365246X.2011.05140.x

41. Reid A.B., Ebbing J., Webb S.J. Comment on "A crustal thickness map of Africa derived from a global gravity field model using Euler deconvolution" by Getachev E. Tedla, M. van der Meijde, A.A. Nyblade and F.D. van der Meer. Geophysical Journal International, 2012, vol. 189, pp. 1217-1222. DOI: 10.1111/j.1365246X.2012.05353.X

42. Rechenmann J., Louis P. Mesure gravimetriques dans le Niger orienta. Années 1963 - 1964 - 1965. Rapport Office de la Recherche Scientifique et Technique Outre-Mer. Paris. 1966.83 p.

43. Louis P., Rechenmann J. Interpretation geologique de certaines anomalies gravimetriques du Tenere (Republique du Niger). Comptes rendus de l'Académie des sciences, Serie D, 1966, t. 263, pp. 476-479. 44. Amante C., Eakins B.W. ETOPO1 - 1 Arc-Minute Global Relief Model: Procedures, Data Sources and Analysis. NOAA Technical Memorandum NESDIS NGDC-24. National Geophysical Data Center, NOAA, 2009. DOI: $10.7289 / \mathrm{V} 5 \mathrm{C} 8276 \mathrm{M}$.

45. Glaznev V.N., Pavlovskiy V.I., Raevskiy A.B. Avtokorrelatchionnye funkchii potenialnyh poley, obuslovlennuh gorizontalinum sloem so slutchainum raspolozheniem istochnikov [Autocorrelation functions of the potential fields due to the random location of sources in horizontal layer]. Physics of Solid Earth, 1978, no. 8, pp. 85-90. (in Russ.)

46. Muravina O.M., Glaznev V.N., Zhavoronkin V.I., Mints M.V. Reflection of the Petrophysical Basement Rocks Models in Geophysical Fields. Eds.: Nurgaliev D, Khairullina N. Springer Proceedings in Earth and Environmental Sciences: Practical and Theoretical Aspects of Geological Interpretation of Gravitational, Magnetic and Electric Fields. Springer Nature Switzerland AG, 2019, pp. 49-54. DOI: 10.1007/978-3-319-97670-9

47. Mints M. V., Glaznev V. N., Muravina O. M., Sokolova E. Yu. 3D model of Svecofennian Accretionary Orogen and Karelia Craton based on geology, reflection seismics, magnetotellurics and density modelling: Geodynamic speculations. Geoscience Frontiers, 2020, vol. 11, no. 3, pp. 999-1023. DOI: 10.1016/j.gsf.2019.10.003

\section{Глазнев Виктор Николаевич - д.ф.-м.н., профессор, заведующий кафедрой геофизики, Воронежский государственный университет, Воронеж, Российская Федерация; E-mail: glaznev@geol.vsu.ru; ORCID https://orcid.org/0000-0002-1016-1866}

Якуба Ибрагим Абдоу - аспирант кафедры геофизики, Воронежский государственный университет, Воронеж, Российская Федерация; E-mail: yibrahimabdou@yahoo.fr Авторы прочитали и одобрили окончательный вариант рукописи.

\author{
Victor N. Glaznev - Dr.habil. in Geophysics and Mathematics, \\ Professor, Head of the Department of Geophysics, Voronezh State \\ University, Voronezh, Russian Federation; \\ E-mail: glaznev@geol.vsu.ru; \\ ORCID https://orcid.org/0000-0002-1016-1866
}

Ibrahim A. Yacouba - postgraduate student, Department of Geophysics, Voronezh State University, Russian Federation; E-mail: yibrahimabdou@yahoo.fr

The authors have read and approved the final manuscript. 